\title{
О перспективах разграничения полномочий в сфере правового регулирования физической культуры и спорта в Российской Федерации
}

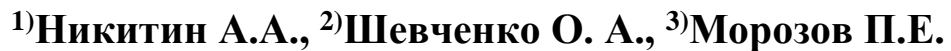 \\ 1)Экспертный совет при Комитете Государственной Думы \\ по физической культуре, спорту, туризму и делам молодежи, \\ Россия, 103265, Москва, Георгиевский пер., д. 2 \\ E-mail: naagdfsrf@gmail.com \\ 2), 3)Университет им. О.Е. Кутафина (МГЮА), \\ Россия, 123995, Москва, ул. Садовая-Кудринская, д. 9 \\ E-mail: labourlaw@bk.ru,pmorozov72@gmail.com
}

\begin{abstract}
Аннотация. Реализация в Конституции Российской Федерации инновационной концепции единой системы публичной власти определяет насущную необходимость нового подхода к вопросам разграничения полномочий между органами государственной власти и органами местного самоуправления по вопросам, связанным с управлением физической культурой и спортом. Существовавший до принятия поправок к Конституции Российской Федерации подход в данной области характеризовался недостаточной эффективностью из-за отсутствия оптимального уровня координации. В связи с этим авторами по результатам анализа законодательства о физической культуре и спорте сделан вывод о том, что концепция единой системы публичной власти, реализованная в Конституции Российской Федерации, способна эффективно справиться с проблемой отсутствия достаточного уровня координации между органами государственной власти и органами местного самоуправления. Комплексный подход, подразумевающий наличие единой задачи, гораздо более эффективен, нежели подход, характеризующийся наличием различных задач в рамках единой стратегии.
\end{abstract}

Ключевые слова: физическая культура, спорт, инновационная конституционная концепция, единая система публичной власти, разграничение полномочий, федеральные органы государственной власти, органы государственной власти субъектов Российской Федерации, органы МСУ.

Для цитирования: Никитин А.А., Шевченко О. А., Морозов П.Е. 2020. О перспективах разграничения полномочий в сфере правового регулирования физической культуры и спорта в Российской Федерации. NOMOTHETIKA: Философия. Социология. Право. 45 (3): 533-541. DOI 10.18413/2712-746X-2020-44-3-533-541

\section{On the prospects for the division of powers in the field of legal regulation of physical culture and sports in the Russian Federation}

\author{
1)Alexander A. Nikitin, ${ }^{2)}$ Olga A. Shevchenko, ${ }^{3)}$ Pavel E. Morozov \\ Expert Council of the State Duma Committee for Physical Culture, Sport, Tourism and Youth, \\ 2 Affairs, Georgievsky lane, Moscow, 103265, Russia \\ e-mail: naagdfsrf@gmail.com \\ 2), 3)Kutafin Moscow State Law University, \\ 9 Sadovaya-Kudrinskaya St, Moscow, 123995, Russia \\ e-mail: labourlaw@bk.ru \\ e-mail: pmorozov72@gmail.com
}

Abstract. The implementation in the Constitution of the Russian Federation of the innovative concept of 
delineation of powers between state authorities and local authorities on issues related to the management of physical culture and sports. The approach in this area that existed before the adoption of the amendments to the Constitution of the Russian Federation was characterized by insufficient efficiency due to the lack of an optimal level of coordination. The author of the article, based on the results of the analysis, concluded that the concept of a unified system of public authority, implemented in the Constitution of the Russian Federation, is able to effectively deal with the problem of the lack of a sufficient level of coordination between state authorities and local authorities. The integrated approach, which implies the presence of a single task, is much more effective than an approach characterized by the presence of different tasks within a single strategy.

Keywords: physical culture, sports, innovative constitutional concept, a unified system of public authority, delineation of powers, federal government bodies, government bodies of the constituent entities of the Russian Federation, local government bodies.

For citation: Nikitin A.A., Shevchenko O.A., Morozov P.E. 2020. On the prospects for the division of powers in the field of legal regulation of physical culture and sports in the Russian Federation. NOMOTHETIKA: Philosophy. Sociology. Law series. 45 (3): 533-541 (in Russian). DOI 10.18413/2712746X-2020-44-3-533-541

\section{Введение}

Реализация в Конституции Российской Федерации инновационной концепции единой системы публичной власти определяет насущную необходимость нового подхода к вопросам разграничения полномочий между федеральными органами государственной власти, органами государственной власти субъектов Российской Федерации и органами местного самоуправления в сфере правового регулирования физической культуры и спорта в Российской Федерации.

Содержание проблемы состоит в том, что существовавший до принятия поправок к Конституции Российской Федерации подход в данной области характеризовался недостаточной эффективностью из-за отсутствия оптимального уровня координации между федеральными органами государственной власти, органами государственной власти субъектов Российской Федерации и органами местного самоуправления, когда каждое звено государственной власти и местного самоуправления зачастую самостоятельно решало задачи правового регулирования физической культуры и спорта. Причем эти задачи в целом не были тесно взаимосвязаны друг с другом, а главное - отсутствовал единый, комплексный подход, у федеральных органов были одни полномочия, у региональных - других. Особо выделялись органы местного самоуправления со своей специфической компетенцией, которые не рассматривались как часть общей системы, что приводило к не вполне успешной реализации программ. Естественно, что все эти обстоятельства сказывались на качестве правового регулирования физической культуры и спорта Российской Федерации.

Убеждены, что концепция единой системы публичной власти, реализованная в Конституции Российской Федерации, способна эффективно справиться с данной проблемой, так как комплексный подход, подразумевающий наличие унифицированных целей и задач, гораздо более эффективен, чем подход, при котором каждый орган решает свои задачи, но не в рамках единой стратегии. Полагаем, что именно единая стратегия в сфере разграничения полномочий на базе концепции единой публичной власти - это залог эффективного решения проблем правового регулирования в области спорта и физической культуры.

\section{Системный подход в сфере публичной службы}

Внедрение системного подхода в сфере публичной службы имеет две составляющие - теоретико-методологическую и практическую (реформирование Федерального закона от 4 декабря 2007 г. № 329-Ф3 «О физической культуре и спорте в Российской Федерации»), которые тесно друг с другом взаимосвязаны. 
Претворение концепции единой системы публичной власти в сфере полномочий Российской Федерации, субъектов Российской Федерации, органов местного самоуправления в области физической культуры и спорта должно ответить на ряд вопросов:

1. Как должна функционировать новая система?

2. В чем состоят взаимосвязи внутри этой системы?

3. Каким образом новая система будет взаимодействовать с другими существующими системами, например, с физкультурно-спортивными организациями?

Анализ проблемы целесообразно начать с ее теоретической составляющей - понятия системы. В методологии выделяют два подхода к дефиниции «система» - дескриптивный (как множество взаимосвязанных элементов) ${ }^{1}$ и конструктивный, подразумевающий наличие определённой цели у этой совокупности взаимосвязанных элементов, для которой создана данная система [Сагатовский, 1976, с. 15].

По нашему мнению, новая система разграничения полномочий между федеральными органами государственной власти, органами государственной власти субъектов Российской Федерации и органами местного самоуправления [Липатов, Чаннов, 2018] в сфере правового регулирования физической культуры и спорта в Российской Федерации должна относиться именно к конструктивным системам. В этом отношении важно определить ее цель. Представляется, что она будет состоять в эффективной реализации и защите прав субъектов физической культуры и спорта. Существенным обстоятельством также будет являться и то, что конструктивная система также должна быть готова решить любую проблему правового регулирования физической культуры и спорта.

В этой связи хотелось бы заострить внимание на вопросе взаимодействия цели и проблемы. Так, в процессе реализации полномочий в сфере физической культуры и спорта органы государственной власти и местного самоуправления могут столкнуться с какой-то проблемой правового регулирования, например, вызванной пробельностью законодательства. В настоящий момент любая проблема в аспекте Федерального закона от 4 декабря 2007 г. № 329-Ф3 «О физической культуре и спорте в Российской Федерации» решается зачастую изолированно с позиции реализации полномочий того или иного уровня государственной власти, а не комплексно. Это обстоятельство, естественно, снижает эффективность, так как, на наш взгляд, проблема, поставленная на уровне федеральных органов для того, чтобы стать разрешенной, должна включать в себя обязательно и план действий на всех уровнях, и на нижестоящих уровнях управления в том числе.

Рассмотрим другой аспект понятия «система».

Признаком любой конструктивной системы является ее эмерджентность, то есть наличие у новой системы свойств, которые не сводятся к свойствам ее элементов. Иными словами, новая система разграничения полномочий между федеральными органами государственной власти, органами государственной власти субъектов Российской Федерации и органами местного самоуправления в сфере правового регулирования физической культуры и спорта в Российской Федерации должна обладать признаками, которые будут отличаться от признаков элементов, ее составляющих (федеральный, региональный и местный уровни государственной власти отдельно).

Проанализируем существующее состояние разграничения полномочий между федеральными органами государственной власти, органами государственной власти субъектов Российской Федерации и органами местного самоуправления в сфере правового регулирования физической культуры и спорта в Российской Федерации, и предложим ряд рекомендаций по реформированию этого разграничения с позиции реализации конституционной концепции единой системы публичной власти [Понкин, 2018].

В настоящий момент вопросам разграничения полномочий между федеральными органами государственной власти, органами государственной власти субъектов Россий-

\footnotetext{
${ }^{1}$ Большой Российский энциклопедический словарь. М. БРЭ. 2003. 1473 с.
} 
ской Федерации и органами местного самоуправления в сфере правового регулирования физической культуры и спорта в Российской Федерации, помимо конституционных положений, посвящены 4 статьи Федерального закона от 4 декабря 2007 г. № 329-Ф3 «О физической культуре и спорте в Российской Федерации»- ст. 6, 8, 9, 9.1.

Если рассматривать закрепление этих полномочий и их виды, то обращает на себя внимание то обстоятельство, что они не составляют единую систему, то есть по сути существуют изолированно друг от друга, что мы рассматриваем как существенную проблему.

Приведем некоторые конкретные примеры.

Так, например, к полномочиям Российской Федерации в области физической культуры и спорта относится разработка и реализация государственной политики в области физической культуры и спорта, принятие и реализация программ развития физической культуры и спорта в Российской Федерации (статья 6 Федерального закона от 4 декабря 2007 г. № 329-Ф3 «О физической культуре и спорте в Российской Федерации»). Вместе с тем в настоящее время данная стратегия не находит свою реализацию на нижестоящих уровнях - субъектов Российской Федерации и органов местного самоуправления.

Действительно, анализ статей 8, 9, 9.1 Федерального закона от 4 декабря 2007 г. № 329-Ф3 «О физической культуре и спорте в Российской Федерации» позволяет заключить, что акцент в них приходится исключительно на региональный и местный уровни: реализация государственных региональных программ развития физической культуры и спорта и межмуниципальных программ в области физической культуры и спорта или определение основных задач и направлений развития физической культуры и спорта с учетом местных условий и возможностей, принятие и реализация местных программ развития физической культуры и спорта.

В этом отношении хотелось бы отметить, что по сути все полномочия разбалансированы, так как на каждом уровне достигается своя цель, решаются собственные проблемы. Иными словами, отсутствует комплексный подход. Таким образом, в процессе реализации конституционной концепции единой системы публичной власти в сфере полномочий в области спорта мы рекомендуем акцентировать внимание на таких признаках системы, как эмерджентность и взаимосвязь элементов системы.

\section{Система разграничения полномочий органов государственной власти и органов местного самоуправления в сфере физической культуры и спорта}

Мы предлагаем такой подход, который бы связал полномочия федеральных органов государственной власти, органов государственной власти субъектов Российской Федерации и органов местного самоуправления в сфере правового регулирования физической культуры и спорта в Российской Федерации в единую систему, которая была бы направлена на достижение общей цели и решение возможных общих проблем.

Самое главное в этом вопросе - одновременные, совместные действия для достижения общей цели на всех уровнях: федеральном, региональном и местном [Чистякова, 2018].

Действительно, в статью 8 и 9 Федерального закона от 4 декабря 2007 г. № 329-Ф3 «О физической культуре и спорте в Российской Федерации» целесообразно включить положение, в соответствие с которым полномочия органов власти субъектов Российской Федерации и местных органов власти должны реализовываться, например, в рамках претворения федеральных программ развития физической культуры и спорта в Российской Федерации.

В этой связи немаловажен и такой признак системы, как взаимосвязь ее элементов: действительно, реализация определенной федеральной программы обязательно должна приводить к реализации программ на региональном и местном уровнях для достижения общей цели [Самолысов, 2018].

Отметим и другой аспект проблемы - по существу в ряде программ в сфере спорта также отсутствует системный подход. Так, в паспорте подпрограммы 8 «Развитие футбола в 
Российской Федерации» государственной программы Российской Федерации «Развитие физической культуры и спорта» (утв. Постановлением Правительства Российской Федерации от 29 марта 2019 г. № 372 «О внесении изменений в государственную программу Российской Федерации «Развитие физической культуры и спорта») вообще отсутствует уровень муниципальных образований, что вряд ли позитивно скажется на достижении цели - создание условий для удовлетворения потребностей населения в занятиях футболом.

Более того, из целевых индикаторов и показателей подпрограммы не вполне ясно, каким образом реализация полномочий федеральных органов и органов власти субъектов Российской Федерации будет способствовать решению задач данной подпрограммы. Можно констатировать в этой связи отсутствие комплексного подхода.

В ряде программ в сфере спорта принцип системности все же соблюдается, что является позитивным обстоятельством. Однако в связи с этим возникают и другие проблемы, так как подобный принцип отсутствует в Федеральном законе от 4 декабря 2007 г. № 329-Ф3 «О физической культуре и спорте в Российской Федерации». Например, Федеральный проект «Спорт - норма жизни» (утв. Постановлением Правительства Российской Федерации от 29 марта 2019 г. № 372 «О внесении изменений в государственную программу Российской Федерации «Развитие физической культуры и спорта») определяет на 2020 год следующее: запущена информационно-коммуникационная кампания по формированию в обществе культуры поведения, основанной на индивидуальной мотивации граждан к физическому развитию, включая подготовку к выполнению и выполнение нормативов Всероссийского физкультурно-спортивного комплекса «Готов к труду и обороне» (ГТО), и стимулированию работодателей к поощрению физической активности персонала. В 352 муниципальных районах созданы центры тестирования Всероссийского физкультурно-спортивного комплекса «Готов к труду и обороне» (ГТО), оборудованные малыми спортивными площадками. В 2 субъектах Российской Федерации, не входящих в состав приоритетных территорий, построены физкультурно-оздоровительные комплексы. Получается достаточно парадоксальная ситуация, когда в программе отражаются идеи единой публичной власти, а в Федеральном законе от 4 декабря 2007 г. № 329-Ф3 «О физической культуре и спорте в Российской Федерации» это отсутствует. Думается, что подобное противоречие можно рассматривать в качестве проблемы. Действительно, программа по сути должна базироваться на нормах закона, а в результате получается, что осуществление полномочий на уровне, например, субъектов и органов местного самоуправления, будет противодействовать ее реализации [Зюрин, Матвеев, 2016].

Рассмотрим вопрос потенциального взаимодействия предлагаемой системы разграничения полномочий с другими системами, которые функционируют в сфере физкультуры и спорта, например, с физкультурно-спортивными организациями [Серпер, Буранок, 2016].

В современных условиях при фактическом отсутствии системы единой публичной власти в сфере физкультуры и спорта само по себе это взаимодействие осуществляется на определенном уровне государственной власти и местного самоуправления. Действительно, например, Олимпийское движение России возглавляется Олимпийским комитетом России - общероссийским общественным объединением, осуществляющим свою деятельность в соответствии с законодательством Российской Федерации об общественных объединениях.

В свою очередь, создание, деятельность, реорганизация и ликвидация местных и региональных спортивных федераций осуществляются в соответствии с законодательством Российской Федерации об общественных объединениях.

Полагаем, что подобное обстоятельство можно рассматривать как некий дисбаланс, так как вопросы деятельности физкультурно-спортивных организаций - это вопросы всей публичной власти без какого-то деления на уровни. 
Особо в Конституции Российской Федерации в новой редакции решается вопрос об органах местного самоуправления (муниципальных образованиях), чей правовой статус определяется специальным законом. В этой связи хотелось бы отметить, что муниципальные образования в настоящее время вошли в систему публичной власти, но вместе с тем они не включаются в систему государственных органов. В этом как раз и состоит их специфика, которая также влияет и на правовое регулирование физкультуры и спорта.

Действительно, с одной стороны, они должны реализовывать свои полномочия с взаимоувязкой с полномочиями федеральных органов и органов субъектов Российской Федерации, но, с другой стороны, эти органы обладают известной независимостью в данном вопросе. Рассмотрим эту специфику более детально.

В Федеральном законе от 6 октября 2003 г. № 131-Ф3 «Об общих принципах организации местного самоуправления в Российской Федерации» уделяется значительное внимание вопросам физической культуры и спорта, но специфика регулирования состоит в том, что физкультура и спорт рассматриваются исключительно с точки зрения органов местного самоуправления в рамках определенных муниципальных образований.

В принципе, подобный подход в аспекте Федерального закона от 4 декабря 2007 г. № 329-Ф3 «О физической культуре и спорте в Российской Федерации» вполне логичен. Однако реализация конституционной концепции единой публичной власти определяет, что полномочия органов местного самоуправления в сфере физкультуры и спорта должны быть в рамках единого подхода с органами государственной власти. Полагаем, что в этом есть определённая дилемма, решение которой нам видится в признании приоритета полномочий органов государственной власти в сфере физкультуры и спорта [Самсонов, 2016].

В этой связи интерес также представляет и Федеральный закон от 13 июля 2015 г. № 224-Ф3 «О государственно-частном партнерстве, муниципально-частном партнерстве в Российской Федерации и внесении изменений в отдельные законодательные акты Российской Федерации» [Григорьев, 2014; Перькова, 2017], в котором еще в 2015 году были предприняты попытки заложить основы единой системы публичной власти в сфере физкультуры и спорта: к объектам соглашения о государственно-частном партнерстве, объектам соглашения о муниципально-частном партнерстве относятся объекты спорта (статья 7).

Важным обстоятельством в данном отношении является тот факт, что в этой норме не разделяются полномочия государственных органов и органов местного самоуправления.

Мы также исходим из того, что возможная реформа федерального законодательства о физической культуре и спорте в целях реализации концепции единой системы публичной власти [Дегтярев, 2019] обязательно отразится и на законодательстве субъектов Российской Федерации, в большинстве из которых действуют нормативные правовые акты по данной проблематике.

Закон г. Москвы от 15 июля 2009 г. № 27 «О физической культуре и спорте в городе Москве» устанавливает, что обеспечение основных направлений развития физической культуры и спорта в городе Москве осуществляется путем утверждения и реализации государственных программ города Москвы в области физической культуры и спорта. На данный момент это положение соответствует федеральному законодательству, однако внедрение концепции единой системы публичной власти со всей неизбежностью приведет к необходимости реформирования данного закона, так как региональные программы будут рассматриваться в качестве средств, механизмов для достижения цели, определенной федеральной программой.

Интересен подход и в другом региональном правовом акте - к полномочиям Губернатора Московской области в области физической культуры и спорта относится определение основных задач и направлений развития физической культуры и спорта в Московской области [Вулах, 2012]. Полагаем, что после реализации концепции единой си- 
стемы публичной власти данное полномочие Губернатора будет рассматриваться уже в аспекте требований органов федеральной власти.

\section{Заключение}

Таким образом, анализ законодательства о физической культуре и спорте [Изаак, 2014; Мифтахов, 2016] позволил сделать вывод о том, что конституционная концепция единой системы публичной власти определяет потребность в пересмотре вопросов разграничения полномочий между федеральными органами государственной власти, органами государственной власти субъектов Российской Федерации и органами местного самоуправления в сфере правового регулирования физической культуры и спорта в Российской Федерации. Реформа необходима для того, чтобы оптимизировать процесс реализации прав граждан в сфере физической культуры и спорта.

Мы понимаем, что данный вопрос не может быть исчерпан лишь одной статьей, требуется целая серия исследований, возможно, и монографического характера.

\section{Список источников}

1. Большой Российский энциклопедический словарь. М. БРЭ. 2003. 1473 с.

1. Федеральный закон от 6 октября 2003 г. № 131-ФЗ «Об общих принципах организации местного самоуправления в Российской Федерации». СЗ РФ. 2003. № 40. Ст. 3822.

2. Федеральный закон от 4 декабря 2007 г. № 329-Ф3 «О физической культуре и спорте в Российской Федерации». СЗ РФ. 2007. № 50. Ст. 6242.

3. Федеральный закон от 13 июля 2015 г. № 224-Ф3 «О государственно-частном партнерстве, муниципально-частном партнерстве в Российской Федерации и внесении изменений в отдельные законодательные акты Российской Федерации». СЗ РФ. 2015. № 29. Ст. 4350.

4. Постановление Правительства РФ от 29 марта 2019 г. № 372. «О внесении изменений в государственную программу Российской Федерации «Развитие физической культуры и спорта». СЗ РФ. 2019. № 14 (часть III). Ст. 1554 (начало).

5. Паспорт национального проекта «Демография» (утв. президиумом Совета при Президенте Российской Федерации по стратегическому развитию и национальным проектам, протокол от 24 декабря 2018 г. № 16).

6. Закон г. Москвы от 15 июля 2009 г. № 27 «О физической культуре и спорте в городе Москве». Вестник Мэра и Правительства Москвы. 2009. № 42.

7. Закон Московской области от 27 декабря 2008 г. № 226/2008-O3 «О физической культуре и спорте в Московской области» (принят постановлением Мособлдумы от 25 декабря 2008 г. № 9/65-П). Ежедневные Новости. Подмосковье. 2008. № 285.

\section{Список литературы}

1. Вулах М.Г. 2012. Управление физической культурой и спортом на региональном уровне. Вестник Саратовской государственной юридической академии, 6 (89): 231-235.

2. Григорьев В.И., Филиппов С.С. 2014. Перспективы развития физической культуры, спорта и туризма России на основе государственно-частного партнерства. Ученые записки университета Лесгафта, 2 (108): 60-66.

3. Дегтярев М.В. 2019. К вопросу о приоритете административного права в обеспечении антидопинговой политики государства. Административное право и процесс, 9: 60-62.

4. Ефимов Г.А. 2019. Разграничение предметов ведения и полномочий «по горизонтали» как способ реализации конституционного принципа разделения властей. Государственная власть и местное самоуправление, 8: 23-30.

5. Зюрин Э.А., Матвеев А.П. 2016. Анализ организационных форм взаимодействия по управлению процессом внедрения комплекса ГТО. Вестник спортивной науки, 6: 50-53

6. Изаак С.И. 2014. Организационно-управленческие аспекты физической культуры и спорта в Хабаровском Крае. Тенденции сохранения уровня здоровья и двигательной активности юношей и девушек, проживающих в условиях Дальневосточного региона, 1: 10-20 
7. Липатов Э.Г., Чаннов С.Е. 2018. Конституционно-правовое регулирование разграничения полномочий в Российской Федерации как способ реализации распределительной политики. Государственная власть и местное самоуправление, 7: 22-27.

8. Мифтахов М.Р. 2016. Анализ эффективности использования спортивных сооружений в Республике Татарстан. Наука и спорт: современные тенденции, 2. 57-64

9. Перькова Е.Ю. 2017. Использование механизма государственно-частного партнерства в спортивной индустрии в РФ. Иннов: электронный научный журнал, 3 (32): 14.

10. Понкин И.В. 2018. Принцип справедливости публичного управления. Под ред. О.А. Кузнецовой и др. Пермский юридический альманах. Ежегодный научный журнал, 1: 99-105.

11. Сагатовский В.Н. 1973. Основы систематизации всеобщих категорий. Томск. Изд-во ТМИ. $431 \mathrm{c.}$

12. Самолысов П.В. 2018. Анализ научных и правовых подходов к определению принципов государственного контроля. $\mathrm{B}$ кн.: Следственная деятельность: настоящее и будущее. Материалы Международной научно-практической конференции. 288-294.

13. Самсонов И.И. 2016. К вопросу о показателях эффективности развития физической культуры и спорта. Проблемы и перспективы развития физической культуры и спорта, 14 (1): 23-26.

14. Серпер С.А., Буранок О.М. 2016. Фитнес в России: проблемы и перспективы федерального и регионального развития. Известия Самарского научного центра Российской академии наук. Социальные, гуманитарные, медико-биологические науки, 1: 14-18.

15. Чистякова К.Д. 2018. Разграничение предметов ведения и полномочий между федерацией и ее субъектами в сфере прав и свобод личности на примере России, Германии и Швейцарии. Конституционное и муниципальное право, 9: 23-27.

\section{References}

1. Vulakh M.G. 2012. Upravlenie fizicheskoi kulturoi i sportom na regionalnom urovne. [Management of physical culture and sports at the regional level]. Vestnik Saratovskoi gosudarstvennoi yuridicheskoi akademii, 6 (89): 231-235.

2. Grigoriev V.I., Filippov S.S. 2014. Perspektivi razvitiya fizicheskoi kulturi_sporta i turizma Rossii na osnove gosudarstvenno_chastnogo partnerstva. [Prospects for the development of physical culture, sports and tourism in Russia on the basis of public-private partnership]. Uchenie zapiski universiteta Lesgafta, 2 (108): 60-66.

3. Degtyarev M.V. 2019. K voprosu o prioritete administrativnogo prava v obespechenii antidopingovoj politiki gosudarstva [On the issue of the priority of administrative law in ensuring the anti-doping policy of the state]. Administrativnoe pravo i process, 9: 60-62.

4. Efimov G.A. 2019. Razgranichenie predmetov vedeniya i polnomochij «po gorizontali» kak sposob realizacii konstitucionnogo principa razdeleniya vlastej [Differentiation of subjects of competence and powers "horizontally" as a way to implement the constitutional principle of separation of powers]. Gosudarstvennaya vlast' i mestnoe samoupravlenie, 8: 23-30.

5. Zyurin E.A., Matveev A.P. 2016. Analiz organizacionnih form vzaimodeistviya po upravleniyu processom vnedreniya kompleksa GTO. [Analysis of organizational forms of interaction to manage the implementation of the TRP complex]. Vestnik sportivnoi nauki, 6: 50-53

6. Izaak S.I. 2014. Organizacionno_upravlencheskie aspekti fizicheskoi kulturi i sporta v Habarovskom Krae. [Organizational and managerial aspects of physical culture and sports in the Khabarovsk Territory]. Tendencii sohraneniya urovnya zdorovya i dvigatelnoi aktivnosti yunoshei i devushek_ projivayuschih v usloviyah Dalnevostochnogo regiona, 1: 10-20

7. Lipatov E.G., Channov S.E. 2018. Konstitucionno-pravovoe regulirovanie razgranicheniya polnomochij v Rossijskoj Federacii kak sposob realizacii raspredelitel'noj politiki [Constitutional and legal regulation of the division of powers in the Russian Federation as a way to implement distribution policy]. Gosudarstvennaya vlast' i mestnoe samoupravlenie, 7: 22-27.

8. Miftakhov M.R. 2016. Analiz effektivnosti ispolzovaniya sportivnih soorujenii v Respublike Tatarstan [Analysis of the effectiveness of the use of sports facilities in the Republic of Tatarstan]. Nauka i sport - sovremennie tendencii, 2: 57-64.

9. Perkova E.Yu. 2017. Ispolzovanie mehanizma gosudarstvenno_chastnogo partnerstva v sportivnoi industrii $v$ RF. [Using the mechanism of public-private partnership in the sports industry in the Russian Federation]. Innov: elektronnii nauchnii jurnal, 3 (32): 14. 
10. Ponkin I.V. 2018. Princip spravedlivosti publichnogo upravleniya [The principle of justice of public administration]. Ed. O.A. Kuznecovoj et al. Permskij yuridicheskij al'manah. Ezhegodnyj nauchnyj zhurnal, 1: 99-105.

11. Sagatovskij V.N. 1973. Osnovy sistematizacii vseobshchih kategorij [Fundamentals of systematization of General categories]. Tomsk. Izd-vo TMI. $431 \mathrm{p}$.

12. Samolysov P.V. 2018. Analiz nauchnih i pravovih podhodov k opredeleniyu principov gosudarstvennogo kontrolya. [Analysis of scientific and legal approaches to defining the principles of state control. Investigative activity: present and future]. In: Sledstvennaya deyatelnost_nastoyaschee i buduschee. [Investigative activity: present and future]. Materials of the International Scientific and Practical Conference, 288-294.

13. Samsonov I.I. 2016. K voprosu o pokazatelyah effektivnosti razvitiya fizicheskoi kulturi i sporta. [To the question of indicators of the effectiveness of the development of physical culture and sports]. Problemi i perspektivi razvitiya fizicheskoi kulturi i sporta, 14 (1): 23-26.

14. Serper S.A., Buranok O.M. 2016. Fitnes v Rossii_ problemi i perspektivi federalnogo i regionalnogo razvitiya. [Fitness in Russia: Problems and Prospects of Federal and Regional Development]. Izvestiya Samarskogo nauchnogo centra Rossiiskoi akademii nauk. Socialnie_ gumanitarnie_mediko_biologicheskie nauki, 1: 14-18.

15. Chistyakova K.D. 2018. Razgranichenie predmetov vedeniya i polnomochij mezhdu federaciej i ee sub"ektami v sfere prav i svobod lichnosti na primere Rossii, Germanii i SHvejcarii [Differentiation of subjects of competence and powers between the Federation and its subjects in the sphere of individual rights and freedoms on the example of Russia, Germany and Switzerland]. Konstitucionnoe i municipal'noe parvo, 9: 23-27.

\section{ИНФОРМАЦИЯ ОБ АВТОРАХ}

Никитин Александр Александрович, ответственный секретарь Экспертного совета при Комитете Государственной Думы по физической культуре, спорту, туризму и делам молодежи, Москва, Россия

Шевченко Ольга Александровна, доктор юридических наук, доцент, профессор кафедры трудового права и права социального обеспечения Университета имени О.Е. Кутафина (МГЮА), Москва, Россия

Морозов Павел Евгеньевич, доктор юридических наук, доцент, профессор кафедры трудового права и права социального обеспечения Университета имени О.Е. Кутафина (МГЮА), Москва, Россия

\section{INFORMATION ABOUT THE AUTHORS}

Alexander A. Nikitin, Executive Secretary of the Expert Council of the State Duma Committee for Physical Culture, Sport, Tourism and Youth Affairs, Moscow, Russia

Olga A. Shevchenko, doctor of legal Sciences, associate Professor, Professor of chair of labor law and social security law University named after O. E. Kutafin (MSAL), Moscow, Russia

Pavel E. Morozov, doctor of legal Sciences, associate Professor, Professor of chair of labor law and social security law University named after $\mathrm{O}$. E. Kutafin (MSAL), Moscow, Russia 